\title{
Benefits and Harms of Mammography Screening for Women With Down Syndrome: a Collaborative Modeling Study
}

\author{
Oguzhan Alagoz, $\mathrm{PhD}^{7}$, Ali Hajjar, $\mathrm{MS}^{\mathrm{l}}$, Sarocha Chootipongchaivat, $\mathrm{MS}^{2}$, \\ Nicolien T. van Ravesteyn, PhD², Jennifer M. Yeh, PhD ${ }^{3}$, Mehmet Ali Ergun, PhD 4 , \\ Harry J. de Koning, MD, $P h D^{2}$, Brian Chicoine, $M D^{5}$, and Barry Martin, $\mathrm{MD}^{6}$
}

'Department of Industrial and Systems Engineering, University of Wisconsin-Madison, Madison, WI, USA; ${ }^{2}$ Erasmus MC, University Medical Center Rotterdam, Rotterdam, Netherlands; ${ }^{3}$ Division of General Pediatrics, Boston Children's Hospital and Harvard Medical School, Boston, MA, USA; ${ }^{4}$ Industrial Engineering Department, Istanbul Șehir University, Istanbul, Turkey; ${ }^{5}$ Advocate Medical Group Adult Down Syndrome Center, Park Ridge, IL, USA; ${ }^{6}$ Division of General Internal Medicine, Department of Medicine, University of Colorado Anschutz Medical Campus, Aurora, CO, USA.

BACKGROUND: Women with Down syndrome have a lower breast cancer risk and significantly lower life expectancies than women without Down syndrome. Therefore, it is not clear whether mammography screening strategies used for women without Down syndrome would benefit women with Down syndrome in the same way.

OBJECTIVE: To determine the benefits and harms of various mammography screening strategies for women with Down syndrome using collaborative simulation modeling. DESIGN: Two established Cancer Intervention and Surveillance Modeling Network (CISNET) simulation models estimated the benefits and harms of various screening strategies for women with Down syndrome over a lifetime horizon.

PARTICIPANTS: We modeled a hypothetical cohort of US women with Down syndrome who were born in 1970.

INTERVENTIONS: Annual, biennial, triennial, and onetime digital mammography screenings during the ages 40 74.

MAIN MEASURES: The models estimated numbers of mammograms, false-positives, benign biopsies, breast cancer deaths prevented, and life-years gained per 1000 screened women when compared with no screening.

KEY RESULTS: In average-risk women 50-74, biennial screening incurred 122 mammograms, 10 false-positive mammograms, and 1.4 benign biopsies per one life-year gained compared with no screening. In women with Down syndrome, the same screening strategy incurred 2752 mammograms, 242 false-positive mammograms, and 34 benign biopsies per one life-year gained compared with no screening. The harm/benefit ratio varied for other screening

Ali Hajjar and Sarocha Chootipongchaivat are joint second authors.

Brian Chicoine and Barry Martin are joint senior authors

A preliminary version of this study was presented at the 2017 Down Syndrome Medical Interest Group-USA Annual Symposium in Sacramento, CA, between July 20 and 23, 2018

Electronic supplementary material The online version of this article (https://doi.org/10.1007/s11606-019-05182-5) contains supplementary material, which is available to authorized users.

Received August 27, 2018

Revised March 20, 2019

Accepted June 7, 2019

Published online August 5, 2019 strategies, and was most favorable for one-time screening at age 50, which incurred 1629 mammograms, 144 falsepositive mammograms, and 20 benign biopsies per one life-year gained compared with no screening.

CONCLUSIONS: The harm/benefit ratios for various mammography screening strategies in women with Down syndrome are not as favorable as those for average-risk women. The benefit of screening mammography for women with Down syndrome is less pronounced due to lower breast cancer risk and shorter life expectancy.

KEY WORDS: screening; mammography; Down syndrome; simulation modeling.

$\mathrm{J}$ Gen Intern Med 34(11):2374-81

DOI: $10.1007 / \mathrm{s} 11606-019-05182-5$

(C) Society of General Internal Medicine 2019

\section{INTRODUCTION}

Mammography screening is widely adopted in the USA as it has been shown to reduce breast cancer mortality. ${ }^{1}$ Although there is no consensus on the optimal age to start and end mammography screening, many medical organizations recommend screening for average-risk women. For instance, the US Preventative Services Task Force (USPSTF) recommends biennial screening between ages 50 and 74 while noting that screening decisions in ages prior to 50 should be an individual one. ${ }^{2}$

Mammography screening guidelines are typically developed for women with average or higher risk of breast cancer and generally do not specify the optimal screening strategy for women with unique characteristics or substantially lower risk of breast cancer. Adult women with Down syndrome, numbering approximately 60,000 in the USA, are one such subgroup of women. ${ }^{3}$ Life expectancy of women with Down syndrome has dramatically increased over time from 25 years in 1983 to close to 60 years as of $2010 .^{4-7}$ Having no established guidelines for women with Down syndrome, clinicians have been following the same adult cancer screening guidelines developed for women without Down syndrome, although such practice may not be optimal due to the 
complexities specific to women with Down syndrome. ${ }^{8}$ Namely, compared with women without Down syndrome, women with Down syndrome are reported to have significantly lower risk of breast cancer and shorter life expectancy. ${ }^{9-11}$ Furthermore, women with Down syndrome have greater risk when undergoing anesthesia, which is typically needed for follow-up procedures such as biopsy, and therefore have a higher risk of complications. ${ }^{12-16}$ Such differences require a careful evaluation of the long-term benefits of screening including breast cancer mortality reduction and life-years gained and harms of screening including false-positives and biopsies with benign outcomes. A cohort study considered mammography screening in women with Down syndrome and found a low yield of invasive breast cancer. ${ }^{17,}{ }^{18}$ However, further assessment is needed to evaluate the potential impact of mammography screening recommendations for women with Down syndrome.

The purpose of this paper is to use collaborative simulation modeling that was used to inform USPSTF's policy recommendations in 2009 and 2016 to estimate the potential harms and benefits of various screening strategies and identify the mammography screening strategy with the most favorable harm/benefit ratio for women with Down syndrome. ${ }^{2,}$ 19, 20

\section{METHODS}

We used two established simulation models that were developed independently as part of the National Cancer Institutefunded CISNET consortium (www.cisnet.cancer.gov): model E (Erasmus University Medical Center, Rotterdam, the Netherlands) and model W (University of Wisconsin-Madison, Madison, Wisconsin, and Harvard Medical School, Boston, Massachusetts). ${ }^{21-23}$ The study was either exempt from human subjects review or approved by review boards at each institution. These models have been used to address many important policy questions related to breast cancer including determining the impact of recent breast density legislation on long-term breast cancer outcomes, ${ }^{24}$ determining the impact of comorbidities on the stopping age for screening and overdiagnosis, ${ }^{25}$ estimating the benefits and costs of the transition from plain-film to digital mammography screening, ${ }^{26}$ and estimating the impact of recent advances in treatment and screening on breast cancer mortality. ${ }^{27}$

Along with other CISNET models, model E and model W were developed independently while making different assumptions and using NCI-funded common inputs including incidence in the absence of screening, mammography dissemination and performance from the Breast Cancer Surveillance Consortium (BCSC), treatment dissemination and effectiveness, and nonbreast cancer causes of death. Models are able to replicate observed breast cancer outcomes such as incidence, mortality, and survival over time and have been validated previously. ${ }^{20,}{ }^{21}$ Models start with the underlying incidence and survival in the absence of screening and treatment and simulate breast cancer- related events for US women until they die by representing four interrelated processes ${ }^{21}$ : (1) breast cancer onset and its natural history; (2) screening and detection; (3) diagnosis, treatment, and survival after diagnosis; (4) death due to non-breast cancer causes. Models are described in detail at http://cisnet.cancer. gov/breast/profiles.html and elsewhere. ${ }^{20,} 22,23,27$

\section{Study Settings}

We used the same simulation settings for average-risk women as in the recent simulations conducted to inform the USPSTF policy update in 2016. Namely, we used a lifetime horizon and simulated hypothetical US women who were born in 1970. We also assumed that the sensitivity and specificity of screening, treatment effectiveness, distribution of breast cancer subtypes, and natural history of the breast cancer are identical for women with and without Down syndrome. The common inputs used for the models are summarized in Online Appendix Table 1.

For women with Down syndrome, we used the same settings that were used in the simulations conducted for informing the USPSTF 2016 policy update except the following input parameters (Online Appendix Table 1):

- Other-cause mortality. We estimated a different othercause mortality input for women with Down syndrome (Fig. 1). For this purpose, we used the study by Glasson et al. ${ }^{28}$ which reports gender-specific survival rates for people with Down syndrome. Our estimates imply that the median age for survival for women with Down syndrome is 57.5 years, consistent with another study focusing on women with Down syndrome in the USA. ${ }^{29}$

- Breast cancer risk. Several studies reported that women with Down syndrome have a significantly lower risk of breast cancer than women without Down syndrome. More specifically, the studies by Hill et al., ${ }^{9}$ Patja et al., ${ }^{10}$ and Hasle et al. ${ }^{11}$ estimate that the risks of breast cancer for women with Down syndrome are 50\%, 40\%, and $16 \%(95 \% \mathrm{CI}, 3-47 \%)$ of that for average-risk women without Down syndrome, respectively. Based on these three studies, we assumed that the underlying breast cancer risk for women with Down syndrome is $25 \%$ of that for average-risk women without Down syndrome for the base case analysis. We then conducted a sensitivity analysis on this parameter to evaluate its impact on our conclusions (see below).

\section{Screening Strategies and Reference Case}

We used the models to estimate the benefits and harms of screening for average-risk women and used these results as a reference. For this purpose, we first estimated the outcomes for no screening and biennial screening between 50 and 74 years old. While the USPSTF recommends biennial screening for women between 50 and 74 years old, it concluded that initiating biennial screening at age 40 , annual screening between 50 and 74 , or annual screening between 40 and 49 followed by 


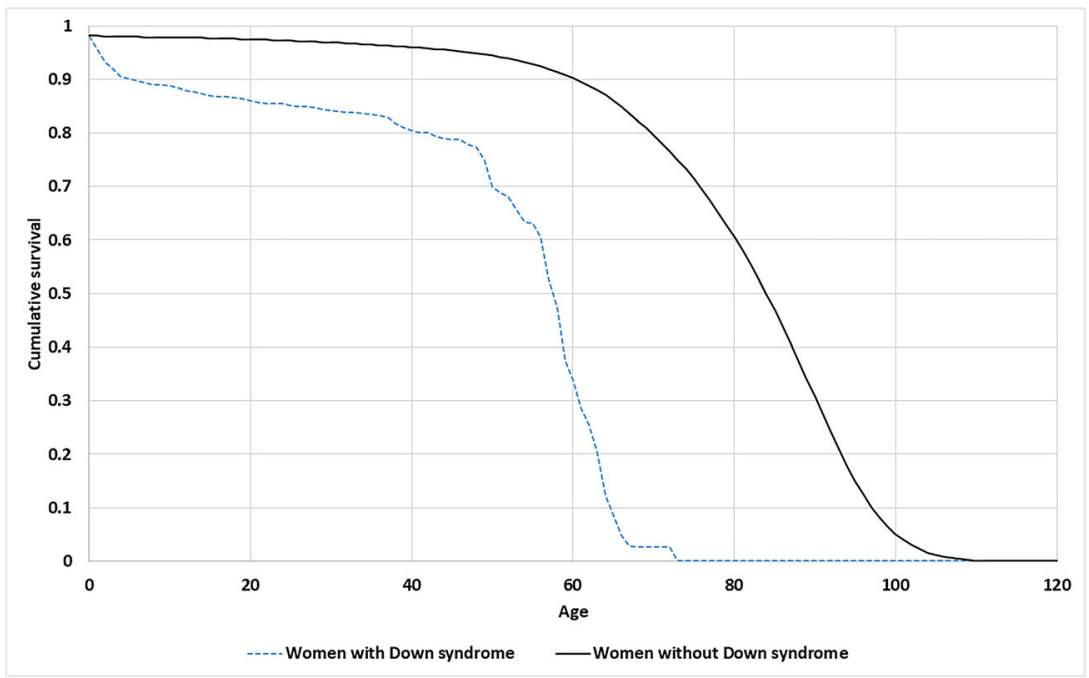

Figure 1 Cumulative survival rates for average-risk women (without Down syndrome) and women with Down syndrome in the absence of breast cancer-related deaths.

biennial screening between 50 and 74 does not have a favorable harm/benefit ratio to recommend universal screening. Therefore, we evaluated the benefits and harms of these three screening strategies for average-risk women and used the range of outcomes as a proxy (or benchmark) for harm/ benefit ratios unlikely to be favorable for women with Down syndrome.

For women with Down syndrome, we evaluated several screening strategies with different starting and stopping times between ages 40 and 74 as well as one-time screening at ages 40,45 , and 50 years. We did not consider stopping ages over 74 since the median age of death for women with Down syndrome is approximately 60 years ( 57.5 years for US women). ${ }^{7,29,30}$

We estimated harms and benefits of screening as well as several harm/benefit ratios. The benefits of screening included life-years gained and breast cancer mortality averted compared with no screening and the harms of screening included number of mammograms, number of false-positives, and number of benign biopsies. We also computed harm/benefit ratios for the number of mammograms, number of false-positive mammograms, and number of benign biopsies per breast cancer death averted and per life-year saved when compared with no screening.

\section{Statistical and Sensitivity Analyses}

Each model estimated the effect of each screening strategy on the benefit and harm metrics over the lifetimes of each simulated woman beginning at age 40 years and then we computed these outcomes per 1000 women alive at age 40 years. All results are presented by taking the average of the results of two models. Note that average incremental harm/benefit ratios are calculated by taking the average of each model's individual estimate for the ratios. Confidence intervals for the models are very narrow and, therefore, are omitted for the clarity of presentation.
We conducted a sensitivity analysis on the baseline risk of breast cancer for women with Down syndrome due to the uncertainty in this parameter. For this purpose, we considered a low estimate for the risk of breast cancer in women with Down syndrome ( $15 \%$ of the breast cancer risk for averagerisk women) and a high estimate for the risk of breast cancer in women with Down syndrome (50\% of the breast cancer risk for average-risk women), and a very high estimate for the risk of breast cancer in women with Down syndrome (100\% of the breast cancer risk for average-risk women). In addition, we considered the case when women with Down syndrome receive cancer treatment according to the observed treatment rates in 2010 instead of a $100 \%$ rate of adherence (i.e., optimal treatment), because cancer treatment may pose additional challenges for these women. ${ }^{31,32}$

\section{RESULTS}

All results in this section are obtained by taking the average of the results of each model and individual model results are presented in the Online Appendix.

\section{Average-Risk Women Without Down Syndrome (Reference Case)}

Under no screening and perfect adherence to treatment, the models estimated that there would be 136 detected cancers and 20.5 breast cancer-related deaths per 1000 average-risk women at age 40 through their lifetime (Table 1). If these women underwent biennial screening between ages 50 and 74 , the models predicted the harm/benefit ratios as 2240 mammograms/averted breast cancer death; 122 mammograms/ life-year (LY) gained; 190 false-positive exam results/averted breast cancer death; 10 false-positive exam results/LY gained; 27 benign biopsies/averted breast cancer death; 1.4 benign 


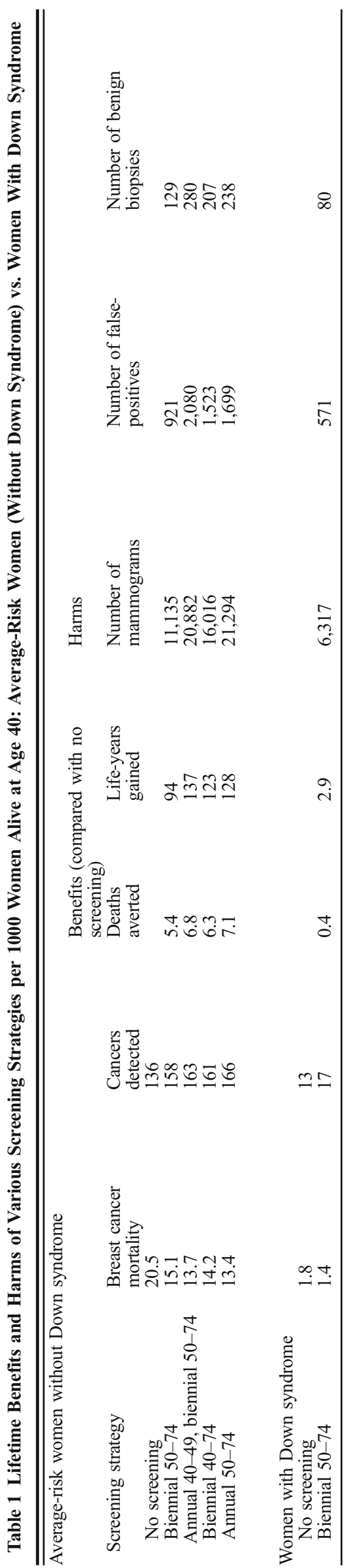

biopsies/LY gained (Fig. 2). The models predicted that initiating biennial screening at age 40 or switching to annual screening between 50 and 74 would have higher harm/benefit ratios compared with biennial screening between 50 and 74 (Fig. 2).

\section{Women With Down Syndrome}

Under no screening, the models estimated that there would be 13 cancers detected (compared with 136 for average-risk women) and 1.8 (compared with 20.5 for average-risk women) breast cancer-related deaths per 1000 women with Down syndrome at age 40 through their lifetime (Table 1). If women with Down syndrome underwent biennial screening between ages 50 and 74, the models predicted that 0.4 breast cancerrelated deaths would be averted and 2.9 additional LYs would be gained for additional 6317 mammograms, 571 falsepositive exam results, and 80 benign biopsies (Table 1). The models predicted the following harm/benefit ratios: 16,735 mammograms/averted breast cancer death; 2752 mammograms/LY gained; 1,493 false-positive exam results/ averted breast cancer death; 242 false-positive exam results/ LY gained; 209 benign biopsies/averted breast cancer death; 34 benign biopsies/LY gained (Table 3). Hence, compared with that of average-risk women, biennial screening between ages 50 and 74 for women with Down syndrome is associated with significantly higher harm/benefit ratios.

Harm/benefit ratios for various stopping and ending ages and frequencies were consistently less favorable (i.e., higher) than those observed for average-risk women (Tables 2 and 3 and Online Appendix Tables 4 and 5). The best harm/benefit ratios were observed when women with Down syndrome are assumed to undergo one-time screening at age 50 . However, none of the screening strategies including one-time screening at age 50 has more favorable harm/benefit ratios than those observed for average-risk women (Fig. 2).

\section{Sensitivity Analysis}

Our sensitivity analysis on the baseline risk of breast cancer found that the incremental harm/benefit ratios were much worse when the baseline risk of breast cancer for Down syndrome women was assumed to be $15 \%$ of the breast cancer risk for average-risk women (Online Appendix Table 6). Even if the baseline risk of breast cancer for Down syndrome women was assumed to be $50 \%$ (highest estimate for the breast cancer risk for women with Down syndrome available in the literature) or $100 \%$ (an extreme assumption, compared with our base assumption of $25 \%$ ) of the breast cancer risk for average-risk women, the harm/benefit ratios were still not as favorable as those obtained for average-risk women (Online Appendix Table 7 and Online Appendix Table 8). Similarly, we observe that the incremental harm/benefit ratios did not change much when women with Down syndrome did not receive optimal treatment (Online Appendix Table 9). 


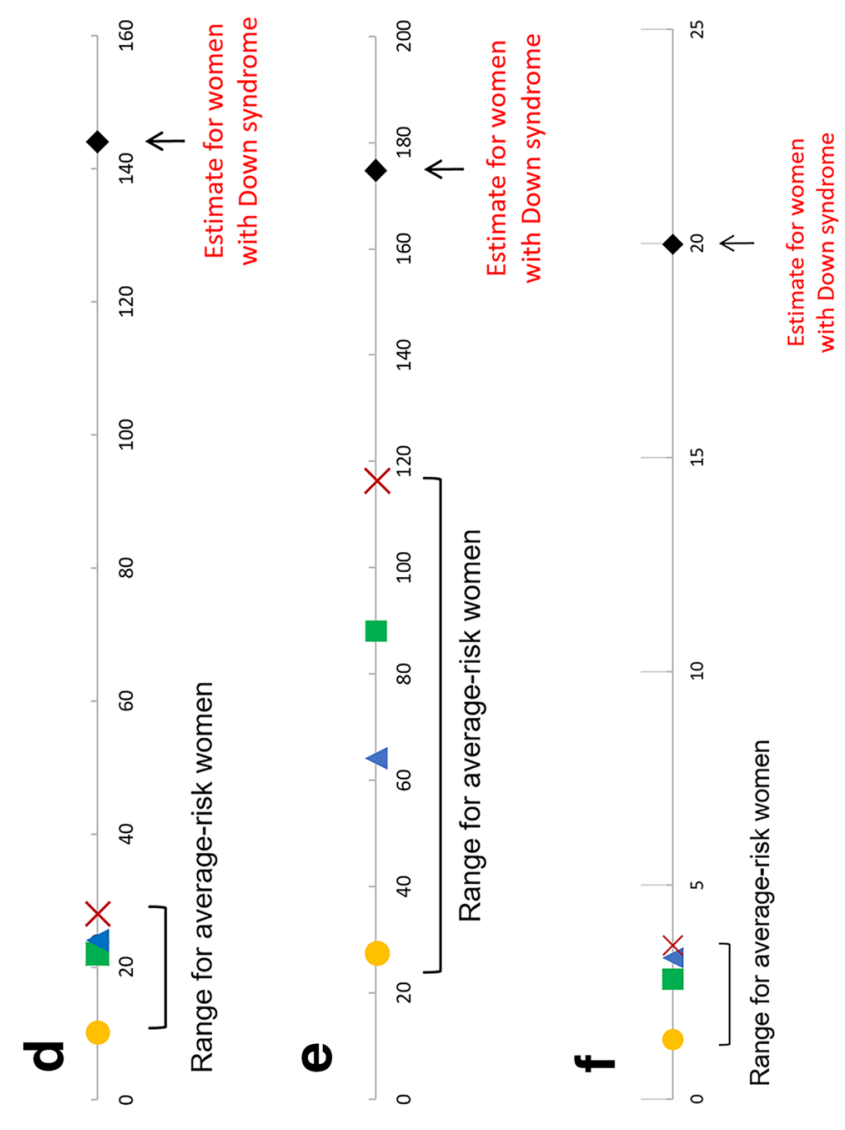

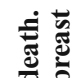

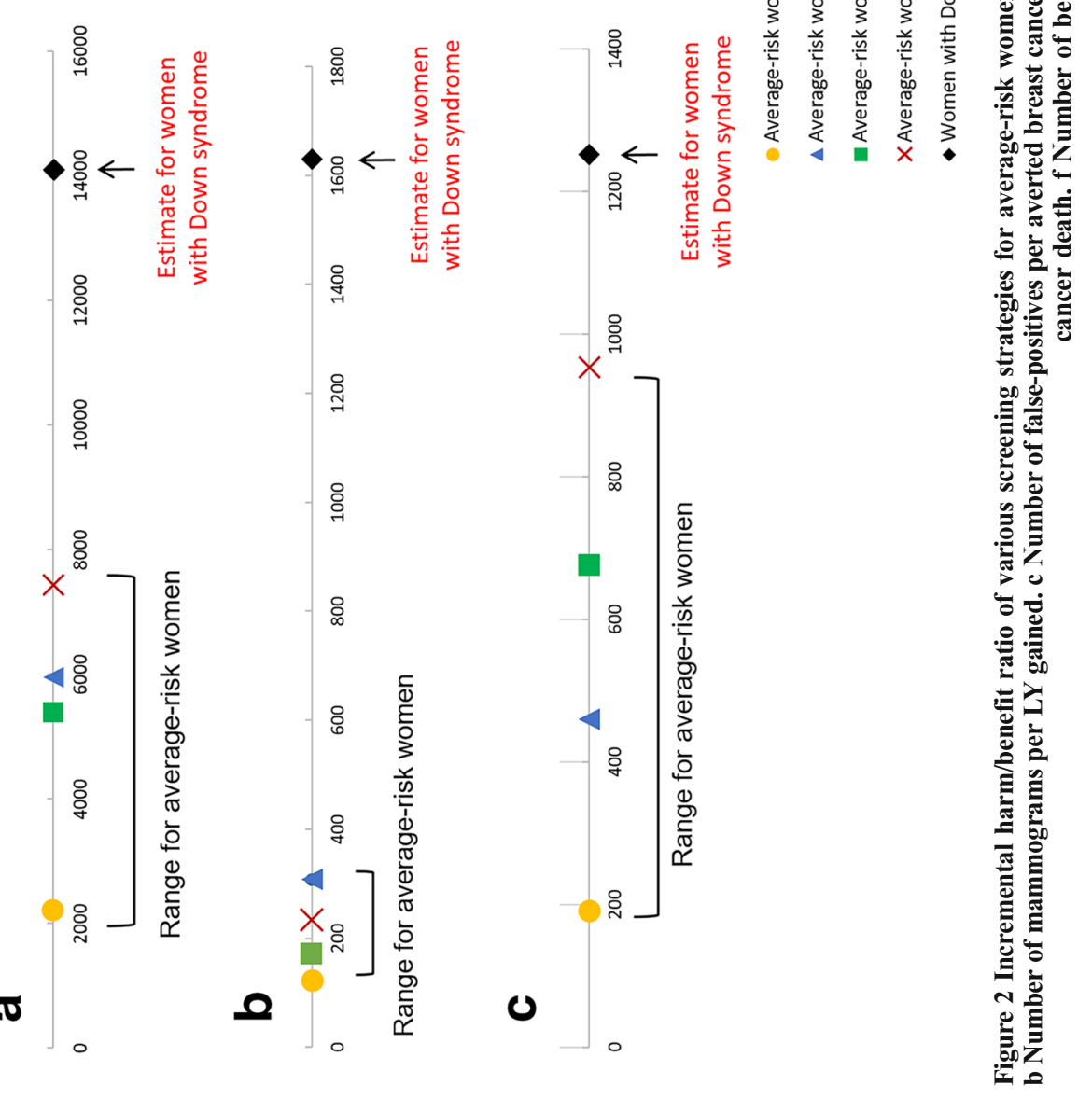


Table 2 Lifetime Benefits and Harms of Various Screening Strategies per 1000 Women With Down Syndrome Alive at Age 40

\begin{tabular}{|c|c|c|c|c|c|c|c|}
\hline \multirow[b]{2}{*}{ Screening Strategy } & \multirow[b]{2}{*}{$\begin{array}{l}\text { Breast cancer } \\
\text { mortality }\end{array}$} & \multirow[b]{2}{*}{$\begin{array}{l}\text { Cancers } \\
\text { Detected }\end{array}$} & \multicolumn{2}{|c|}{$\begin{array}{l}\text { Benefits (compared with } \\
\text { no screening) }\end{array}$} & \multicolumn{3}{|l|}{ Harms } \\
\hline & & & $\begin{array}{l}\text { Deaths } \\
\text { averted }\end{array}$ & $\begin{array}{l}\text { Life years } \\
\text { gained }\end{array}$ & $\begin{array}{l}\text { Number of } \\
\text { mammograms }\end{array}$ & $\begin{array}{l}\text { Number of } \\
\text { false-positives }\end{array}$ & $\begin{array}{l}\text { Number of } \\
\text { benign biopsies }\end{array}$ \\
\hline $\begin{array}{l}\text { No screening } \\
\text { One-time screening } \\
\text { only }\end{array}$ & 1.8 & 13 & & & & & \\
\hline Screen at age 40 & 1.8 & 13 & 0.0 & 0.5 & 997 & 121 & 16 \\
\hline Screen at age 45 & 1.8 & 13 & 0.0 & 0.5 & 970 & 117 & 15 \\
\hline Screen at age 50 & 1.8 & 13 & 0.1 & 0.6 & 928 & 82 & 12 \\
\hline $\begin{array}{l}\text { Biennial } 50-74 \\
\text { (USPSTF } \\
\text { recommendation) }\end{array}$ & 1.4 & 17 & 0.4 & 2.9 & 6,317 & 571 & 80 \\
\hline
\end{tabular}

\section{DISCUSSION}

This collaborative modeling study shows that the harm/benefit ratio of mammography screening for women with Down syndrome is not as favorable as that for average-risk women, implying that common breast cancer screening guidelines developed for average-risk women are suboptimal for women with Down syndrome. The most favorable harm/benefit ratios were observed for the one-time screening at age 50, although that strategy still did not have a favorable harm/benefit ratio when compared with that for biennial screening between ages 50 and 74 in average-risk women. The models consistently predicted that none of the commonly used mammography screening strategies would achieve a favorable harm/benefit ratio even when women with Down syndrome are assumed to have a higher breast cancer risk than the observed levels. The benefit of screening mammography for women with Down syndrome is limited due to lower breast cancer risk and shorter life expectancy.

On the other hand, as the weighting of benefits and harms of screening is a personal choice, some clinicians and/or caregivers may lead to different conclusions on the benefits and harms of screening. To this end, clinicians and caregivers may use our models' estimates for the harms and benefits of screening to decide that harm/benefit ratios observed under certain screening strategies are favorable enough to recommend screening. In particular, screening may be preferred for relatively high-risk women with Down syndrome such as those with family history of breast cancer or high breast density.
No previous study evaluated the lifetime impact of mammography screening on women with Down syndrome; therefore, a direct comparison to previous studies is not possible. However, one recent study examined the mammography reports of women with Down syndrome treated in the largest medical facility specifically serving adults with Down syndrome in the USA over a 16-year period, and found that only two women were detected with cancer among 993 mammography reports. ${ }^{18}$ Neither patient had invasive breast cancer, neither fully complied with treatment recommendations, neither had breast cancer recurrence or metastases, and both patients ultimately died due to Alzheimer disease at ages 55 and $63 .{ }^{18}$ Our study's findings are consistent with this study which also concluded that the harms of mammography screening potentially outweighed the benefits.

Our study did not consider the potential quality-of-life impacts of screening whereas mammography screening and follow-up procedures may have more detrimental effects on women with Down syndrome compared with women without Down syndrome. For instance, the study by Chicoine et al. ${ }^{18}$ reports that, among 684 patients included in the study, 51 women could not cooperate with mammograms and radiology departments requested that "providers not refer some women with Down syndrome for subsequent mammograms because the experience was too frightening and overwhelming for the patients, making the procedure 'dangerous' for both the patients and the radiology technicians." If the models had included the adverse quality-of-life effects of undergoing screening and evaluation of false-positives, benefits of screening

Table 3 Incremental Harm/Benefit Ratios of Various Screening Strategies for Women With Down Syndrome

\begin{tabular}{|c|c|c|c|c|c|c|}
\hline \multirow[t]{2}{*}{ Screening strategy } & \multicolumn{6}{|c|}{ Incremental harm/benefit ratio (compared with no screening) } \\
\hline & $\begin{array}{l}\text { Number of } \\
\text { mammograms/ } \\
\text { averted breast cancer } \\
\text { death }\end{array}$ & $\begin{array}{l}\text { Number of } \\
\text { mammograms/LY } \\
\text { gained }\end{array}$ & $\begin{array}{l}\text { Number of } \\
\text { false-positives/ } \\
\text { averted breast } \\
\text { cancer death }\end{array}$ & $\begin{array}{l}\text { Number of } \\
\text { false- } \\
\text { positives/LY } \\
\text { gained }\end{array}$ & $\begin{array}{l}\text { Number of } \\
\text { benign biopsies/ } \\
\text { averted breast } \\
\text { cancer death }\end{array}$ & $\begin{array}{l}\text { Number of } \\
\text { benign } \\
\text { biopsies/LY } \\
\text { gained }\end{array}$ \\
\hline \multicolumn{7}{|l|}{ One-time screening only } \\
\hline Screen at age $40^{\circ}$ & 30,669 & 1,887 & 3,726 & 228 & 484 & 30 \\
\hline Screen at age 45 & 24,133 & 2,072 & 2,925 & 250 & 380 & 32 \\
\hline Screen at age 50 & 14,105 & 1,629 & 1,252 & 144 & 175 & 20 \\
\hline $\begin{array}{l}\text { Biennial 50-74 } \\
\text { (USPSTF recommen- } \\
\text { dation) }\end{array}$ & 16,735 & 2,752 & 1,493 & 242 & 209 & 34 \\
\hline
\end{tabular}


would have been lower. This finding also implies that there is an increased need for training of medical providers to support women with Down syndrome as well as women with intellectual disability that need to undergo mammography.

Our study has several limitations. First, due to the limited breast cancer-related data for women with Down syndrome, we assumed that the performance of screening, treatment effectiveness, and breast cancer subtype distributions for these women are the same as those for women without Down syndrome. Secondly, an important parameter affecting the outcomes is breast cancer risk for women with Down syndrome, which depends on the three studies in the literature that are highly discordant. The discrepancy of these studies in estimating the breast cancer risk for women with Down syndrome is primarily due to small sample sizes. In order to overcome this limitation, we conducted an extensive sensitivity analysis on breast cancer risk for women with Down syndrome and reported the outcomes for various breast cancer risk levels. Thirdly, we did not evaluate quality-of-life outcomes such as quality-adjusted life-years due to lack of such data for women without Down syndrome. Similarly, we did not estimate the rates of overdiagnosis, a major harm of screening as there is a high level of uncertainty in the actual rates of overdiagnosis. ${ }^{33}$ However, we expect overdiagnosis rates to be higher for women with Down syndrome compared with average-risk women due to lower life expectancy. Furthermore, as life expectancy for women with Down syndrome continues to improve, our findings on harms and benefits of mammography screening need to be revisited since our parameter estimates are based on earlier birth cohorts whereas we model women who were born in 1970. Finally, our study does not account for the other benefits of screening mammography for women with Down syndrome including its role in the normalization of an underserved population.

In summary, we found that the harm/benefit ratios for various mammography screening strategies in women with Down syndrome are not as favorable as those in average-risk women. Our study could be used to guide providers in discussion with patients and families and we encourage national organizations to consider a modification of screening guidelines for the subpopulation of women with Down syndrome or other subpopulations that have unique characteristics.

ACKNOWLEDGMENTS: Collection of Breast Cancer Surveillance Consortium (BCSC) data used in this study was supported by National Cancer Institute Grants P01CA154292, U54CA163303, and HHSN261201100031C.

Corresponding Author: Oguzhan Alagoz, PhD; Department of Industrial and Systems Engineering, University of Wisconsin-Madison, Madison, WI, USA (e-mail: alagoz@engr.wisc.edu).

Funding This work was supported by the National Institutes of Health under National Cancer Institute Grants UO1CA152958.

\section{Compliance with ethical standards:}

The content is solely the responsibility of the authors and does not necessarily represent the official views of the National Institutes of Health.

Conflict of Interest: The authors declare that they do not have a conflict of interest.

\section{REFERENCES}

1. Myers ER, Moorman P, Gierisch JM, Havrilesky LJ, Grimm LJ, Ghate S, et al. Benefits and harms of breast cancer screening: a systematic review. Jama. 2015;314(15): 1615-34.

2. Siu AL. Screening for breast cancer: US preventive services task force recommendation StatementScreening for breast cancer. Ann Intern Med. 2016;164(4):279-96.

3. de Graaf G, Buckley F, Skotko BG. Estimation of the number of people with Down syndrome in the United States. Genet Med. 2016;19(4):43947.

4. Yang Q, Rasmussen SA, Friedman J. Mortality associated with Down's syndrome in the USA from 1983 to 1997: a population-based study. Lancet. 2002;359(9311):1019-25.

5. Glasson E, Sullivan S, Hussain R, Petterson B, Montgomery P, Bittles A. The changing survival profile of people with Down's syndrome: implications for genetic counselling. Clin Genet. 2002;62(5):390-3.

6. Zhu JL, Hasle H, Correa A, Schendel D, Friedman J, Olsen J, et al. Survival among people with Down syndrome: a nationwide populationbased study in Denmark. Genet Med. 2012;15(1):64-9.

7. Englund A, Jonsson B, Zander CS, Gustafsson J, Annerén G. Changes in mortality and causes of death in the Swedish Down syndrome population. Am J Med Genet A. 2013;161(4):642-9.

8. Satgé $\mathbf{D}$, Sasco AJ. Breast screening guidelines should be adapted in Down's syndrome. BMJ: Br Med J. 2002;324(7346):1155.

9. Hill DA, Gridley G, Cnattingius S, Mellemkjaer L, Linet M, Adami HO, et al. Mortality and cancer incidence among individuals with Down syndrome. Arch Intern Med. 2003;163(6):705-11.

10. Patja K, Pukkala E, Sund R, Iivanainen M, Kaski M. Cancer incidence of persons with down syndrome in Finland: a population-based study. Int J Cancer. 2006;118(7):1769-72.

11. Hasle H, Friedman JM, Olsen JH, Rasmussen SA. Low risk of solid tumors in persons with Down syndrome. Genet Med. 2016.

12. Al-Biltagi M. Chapter: Anesthesia in Down Syndrome Children. Down Syndrome Children-An Update. Bentham Science Publishers; 2015.

13. Bhattarai B, Kulkarni AH, Rao ST, Mairpadi A. Anesthetic consideration in downs syndrome-a review. 2008.

14. Borland LM, Colligan J, Brandom BW. Frequency of anesthesia-related complications in children with Down syndrome under general anesthesia for noncardiac procedures. Pediatr Anesth. 2004;14(9):733-8.

15. Meitzner MC, Skurnowicz JA. Anesthetic considerations for patients with Down syndrome. AANA J. 2005;73(2).

16. Butler MG, Hayes BG, Hathaway MM, Begleiter ML. Specific genetic diseases at risk for sedation/anesthesia complications. Anesth Analg. 2000;91(4):837-55.

17. Satge D, Sasco A, Pujol H, Rethore M. Breast cancer in women with trisomy 21. Bull Acad Natl Med. 2001;185(7):1239-52; discussion 52-4.

18. Chicoine B, Roth M, Chicoine $\mathbf{L}$, Sulo S. Breast cancer screening for women with Down syndrome: Lessons learned. Intellect Dev Disabil. 2015;53(2):91-9.

19. Mandelblatt JS, Cronin KA, Bailey S, Berry DA, de Koning HJ, Draisma G, et al. Effects of mammography screening under different screening schedules: model estimates of potential benefits and harms. Ann Intern Med. 2009; 151(10):738-47.

20. Mandelblatt JS, Stout NK, Schechter CB, Van Den Broek JJ, Miglioretti DL, Krapcho M, et al. Collaborative modeling of the benefits and harms associated with different US breast cancer screening strategies. Ann Intern Med. 2016;164(4):215-25.

21. Alagoz O, Berry DA, de Koning H, Feuer EJ, Lee SJ, Plevritis SK, et al. Introduction to the Cancer Intervention and Surveillance Modeling Network (CISNET) Breast Cancer Models. Med Decis Mak. 2018;38(1S). https://doi.org/10.1177/0272989X17737507.

22. Alagoz O, Ergun MA, Cevik M, Sprague BL, Fryback DG, Gangnon RE, et al. The University of Wisconsin Breast Cancer Epidemiology 
Simulation Model: An Update Med Decis Mak. 2018;38(1S). https://doi. org/10.1177/0272989X17711927.

23. van den Broek JJ, van Ravesteyn NT, Heijnsdijk EA, de Koning $H$ Estimating the effects of risk-based screening and adjuvant treatment using the MISCAN-Fadia continuous tumor growth model for breast cancer. Med Decis Mak. 2017; In Press.

24. Sprague BL, Stout NK, Schechter C, van Ravesteyn NT, Cevik M, Alagoz O, et al. Benefits, harms, and cost-effectiveness of supplemental ultrasonography screening for women with dense breasts. Ann Intern Med. 2015;162(3):157-66.

25. Van Ravesteyn NT, Stout NK, Schechter CB, Heijnsdijk EA, Alagoz O, Trentham-Dietz A, et al. Benefits and harms of mammography screening after age 74 years: model estimates of overdiagnosis. J Natl Cancer Inst. 2015;107(7):djv103.

26. Stout NK, Lee SJ, Schechter CB, Kerlikowske K, Alagoz O, Berry D et al. Benefits, harms, and costs for breast cancer screening after US implementation of digital mammography. J Natl Cancer Inst. 2014;106(6):dju092.

27. Plevritis SK, Munoz D, Kurian AW, Stout NK, Alagoz O, Near AM, et al. Association of Screening and Treatment With Breast Cancer Mortality by Molecular Subtype in US Women, 2000-2012. JAMA. 2018;319(2):154-64.

28. Glasson E, Sullivan S, Hussain R, Petterson B, Montgomery P, Bittles A. Comparative survival advantage of males with Down syndrome. Am J Hum Biol. 2003;15(2):192-5.
29. Day SM, Strauss DJ, Shavelle RM, Reynolds RJ. Mortality and causes of death in persons with Down syndrome in California. Dev Med Child Neurol. 2005;47(3):171-6.

30. Torr J, Strydom A, Patti P, Jokinen N. Aging in Down syndrome: Morbidity and mortality. J Pol Pract Intell Disabil. 2010;7(1):70-81.

31. Satgé D, Kempf E, Dubois J-B, Nishi M, Trédaniel J. Challenges in Diagnosis and Treatment of Lung Cancer in People with Intellectual Disabilities: Current State of Knowledge. Lung Cancer Int. 2016;2016.

32. Miller J, Ding L, Spaeth J, Lam J, Paquin J, Lin E, et al. Sedation methods for transthoracic echocardiography in children with Trisomy 21-a retrospective study. Pediatr Anesth. 2017;27(5):531-9.

33. Independent UK Panel on Breast Cancer Screening. The benefits and harms of breast cancer screening: an independent review. Lancet. 2012;380(9855): 1778-86.

Publisher's Note Springer Nature remains neutral with regard to jurisdictional claims in published maps and institutional affiliations. 